\title{
Facile and green synthesis of silver nanoparticle-reduced graphene oxide composite and its application as nonenzymatic electrochemical sensor for hydrogen peroxide
}

\author{
Jagdish C. Bhangoji ${ }^{a}$, Srikant Sahoo ${ }^{b}$, Ashis Kumar Satpatib and Suresh S. Shendage ${ }^{a^{*}}$
}

${ }^{a}$ Department of Chemistry, KET's V. G. Vaze College, Mithagar Road, Mulund (E), Mumbai-400081, India

${ }^{b}$ Analytical Chemistry Division, Bhabha Atomic Research Centre, Homi Bhabha National Institute, Trombay, Mumbai-400085

\begin{tabular}{l} 
C H R O N I C L E \\
\hline Article history: \\
Received November 18, 2020 \\
Received in revised form \\
March 10, 2021 \\
Accepted March 10, 2021 \\
Available online \\
March 10, 2021 \\
Keywords: \\
Electrocatalysis \\
Electrochemical sensors \\
Hydrogen peroxide \\
rGO \\
Silver NPs
\end{tabular}

\section{Introduction}

It is well known that hydrogen peroxide $\left(\mathrm{H}_{2} \mathrm{O}_{2}\right)$ is an essential constituent in food, pharmaceutical, textile, chemical, biochemical, clinical industries and environmental analysis. It is also formed in oxidase enzyme catalyzed reactions as a by-product. $\mathrm{H}_{2} \mathrm{O}_{2}$ is a potential poison once entered inside the cell through the cell membrane. About $3 \% \mathrm{H}_{2} \mathrm{O}_{2}$ is an important household disinfectant, however the same concentration of the reagent has the potential to kill several cells if entered in the human body and cause severe health hazards. $\mathrm{H}_{2} \mathrm{O}_{2}$ is a metastable oxygen species, decomposes to generate highly reactive hydroxyl radicals, the main cause of the peroxide toxicity. Once $\mathrm{H}_{2} \mathrm{O}_{2}$ gets inside the cell, it oxidizes the $\mathrm{Fe}(\mathrm{II})$ in hemeproteins and generates the hydroxyl radicals, which causes DNA damage in addition to several other complicated reactions ${ }^{1}$. Therefore, sensitive, accurate, rapid and reliable detection of hydrogen peroxide is utmost important ${ }^{2-6}$. In recent years, numerous methods have been developed for the detection of $\mathrm{H}_{2} \mathrm{O}_{2}$, which includes titrimetry ${ }^{7}$, fluorescence ${ }^{8}$, electrochemiluminescence ${ }^{9}$, spectrophotometry ${ }^{10}$ and electrochemistry ${ }^{11}$. Among these reported methods, the * Corresponding author. Tel.: +91-22-2163-1421/1423; fax: +91-22-2163-4262

E-mail address: sureshsshendage@gmail.com (S. S. Shendage)

(C) 2021 Growing Science Ltd. All rights reserved. doi: $10.5267 /$ j.ccl.2021.3.002

\begin{abstract}
A simple and environment friendly protocol has been developed for the synthesis of $\mathrm{Ag}$ nanoparticles (AgNPs) supported on reduced graphene oxide (rGO) with copper metal foil as reductant. The prepared AgNPs-rGO, nanocomposite was characterized by various analytical microscopy (FE-SEM), X-ray diffraction (XRD). The electrochemical performance of the material has been evaluated using cyclic voltammetry (CV), chronoamperometry and electrochemical impedance spectroscopy (EIS). The average crystallite size of AgNPs is found sensor is examined through the modified electrode with the synthesized AgNPs-rGO The sensor showed excellent performance toward $\mathrm{H}_{2} \mathrm{O}_{2}$ reduction with a sensitivity of 12.73 $\mu \mathrm{A} . \mathrm{cm}^{-2} \cdot \mathrm{mM}^{-1}$, with a linear dynamic range of $1.5 \mu \mathrm{M}-100 \mathrm{mM}$, and the detection limit of $1.90 \mu \mathrm{M}(\mathrm{S} / \mathrm{N}=3)$. Furthermore, the sensor displayed high sensitivity, reproducibility, stability
and selectivity for the determination of $\mathrm{H}_{2} \mathrm{O}_{2}$. The results demonstrated that AgNPs-rGO has potential applications as sensing material for quantitative determination of $\mathrm{H}_{2} \mathrm{O}_{2}$.
\end{abstract}

(C) 2021 Growing Science Ltd. All rights reserved. 
electrochemical method has been widely used owing to its advantages such as accuracy, sensitivity, selectivity, low cost, high efficiency greener, fast and most importantly simple for field application ${ }^{3,12}$. In recent time, the nanocomposite of carbonaceous material such as graphite, graphene oxide, reduced graphene oxide and MWCNT have been reported as support for the deposition of metal nanostructures. The other hybrid catalysts such as hierarchical $\mathrm{Sn}_{3} \mathrm{O}_{4}$ decorated with $\mathrm{Ag}, \mathrm{Pt}, \mathrm{Au}$, and polymer-metal composite have been used in the $\mathrm{H}_{2} \mathrm{O}_{2}$ sensor applications because nanoparticles have unique structural and morphological properties which improve catalytic activity of sensor ${ }^{13-19}$. Among these, the silver nanoparticles (AgNPs) have gained much attention because of their excellent electrocatalytic activity in sensor applications ${ }^{5,20-26}$.

Graphene is a one-atom-thick, single-layer planar sheet of carbon having hexagonal sp ${ }^{2}$-hybridized carbon. The researchers are fascinated towards the use of graphene because of its unique properties such as high surface area, electrical, mechanical, thermal, and optical properties ${ }^{27}$. These exceptional properties have made graphene as widely applicable material in various advanced fields such as nanoelectronics, sensors, capacitors, drug delivery, hydrogen storage, electromagnetic shield, ceramic materials, fuel cells, batteries, solar cell, metal matrix composites as well as conductive paints and inks. The sensing capacity of composite material depends upon the size, shape, and monodispersion of metal NPs on support material ${ }^{28}$. Several earlier reports demonstrated that metal NPs supported on graphene have a high catalytic activity and high electron transfer rate of metal nanomaterials as compared to graphene oxide ${ }^{28,29-31}$. As a result, graphene support is useful for achieving high dispersion of AgNPs, over and above its particular size and shape ${ }^{32}$. It was observed that $\mathrm{rGO}$ is an excellent support material for the development of metal-graphene nanocomposite ${ }^{20-22}$ The researchers shown that metal nanoparticles deposited on reduced graphene oxide has greater advantages in the sensor applications ${ }^{21}$ over the other support material due to its improved electrochemical properties. ${ }^{2,20}$ Recently, AgNPs have been synthesized using various physical and chemical methods such as, chemical reduction, ${ }^{12,20,22}$ microemulsion/reverse micelles, ${ }^{32}$ electrochemical reductions, ${ }^{11,33,34}$ ultrasonic irradiations, ${ }^{4}$ Biosynthesis method ${ }^{2,35-36}$ and photochemical reduction. ${ }^{37}$ In recent times various publications have focused on developing new approach for the synthesis of metal nanoparticles. These publications reported complicated catalyst fabrication methods. The preparation of the metal NPs composites with controlled morphology of nanostructures in a simple and cost-effective way is challenging. Some of the earlier reported methods suffer from drawbacks such as, toxic chemicals, stabilizers, long duration, less yield and high cost. To overcome these drawbacks, there is a need of designing cost effective electrocatalyst for the fabrication of $\mathrm{H}_{2} \mathrm{O}_{2}$ sensors. Additionally, the redox process of $\mathrm{Ag}$ to $\mathrm{Ag}(\mathrm{I})$ is highly labile so it is able to catalyse the reduction process of $\mathrm{H}_{2} \mathrm{O}_{2}$ to water. Presence of $\mathrm{Ag}$ nanoparticles in composite with rGO has the additional advantage of charge mobility through rGO network along with getting the platform for the reduction process of $\mathrm{H}_{2} \mathrm{O}_{2}$. Besides, good electrical conductivity, high surface area and high catalytic activity made AgNPs applicable for catalytic reduction process of $\mathrm{H}_{2} \mathrm{O}_{2}$ which has been designed in the present case. ${ }^{38-42}$

In this paper, we report the novel protocol for synthesis of AgNPs on rGO support without using toxic reducing agents, stabilizing agents and heat. In this protocol copper metal foil was used as a reducing agent to reduce silver ions into silver nanoparticles and deposited them on rGO. The driving force for the reduction of $\mathrm{Ag}$ ions by $\mathrm{Cu}$ metal is the difference in their standard reduction potential $\left(\mathrm{E}^{0} \mathrm{Ag}^{+} / \mathrm{Ag}=0.79 \mathrm{~V} \& \mathrm{E}^{0} \mathrm{Cu}^{2+} / \mathrm{Cu}=0.34 \mathrm{~V}\right)$. Furthermore, the oxidized copper ions during the redox process were also regenerated by electrochemical deposition and it can be recycled for several times. Moreover, so far no attention has been paid for synthesis of AgNPs deposited on reduced graphene oxide (rGO) with copper metal as reducing agent for $\mathrm{H}_{2} \mathrm{O}_{2}$ sensing application. A non-enzymatic sensor was fabricated by modifying glassy carbon electrodes with the prepared AgNPs-rGO, which was applied for electrochemical detection of $\mathrm{H}_{2} \mathrm{O}_{2}$ (Scheme1). The electrochemical, morphology, chemical composition and electrocatalytic activity of the AgNPs decorated rGO nanocomposite was investigated in detail and it has been targeted to develop a highly sensitive and selective analytical method with low detection limit. 


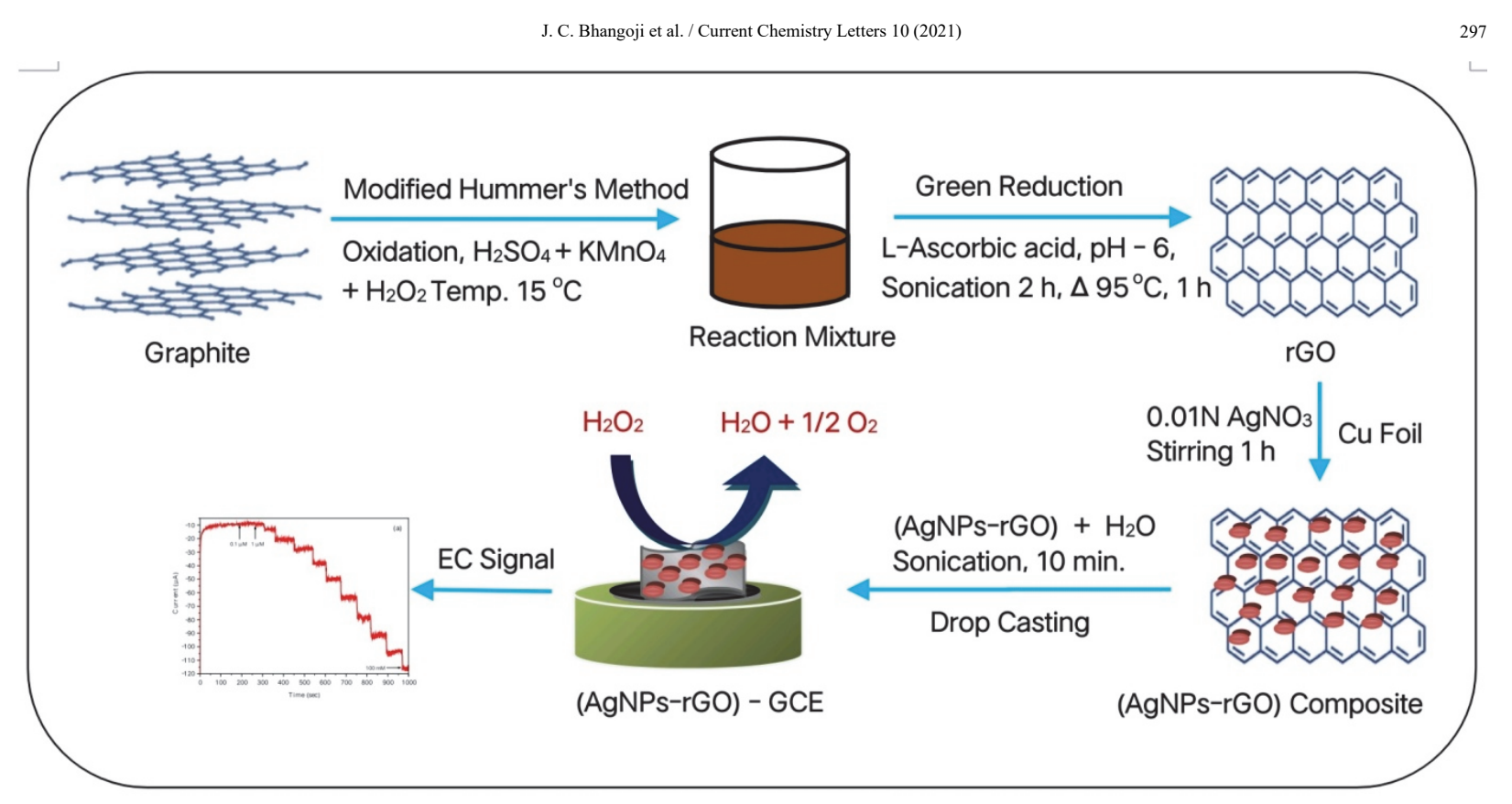

Scheme 1. Schematic representation of synthesis of AgNPs-rGO composite and its electrochemical application for $\mathrm{H}_{2} \mathrm{O}_{2}$.

\section{Results and Discussion}

\subsection{Structural and morphological characterization of Ag NPs-rGO Composite}

The UV-Vis reflectance measurements of rGO and the AgNPs-rGO composite were carried out and the results are shown in Fig. 1a. The reflectance spectrum of rGO generated two peaks, one with a small hump at $252 \mathrm{~nm}$ and the other at $313 \mathrm{~nm}$. The peak at $252 \mathrm{~nm}$ corresponds to the $\pi$ to $\pi^{*}$ electronic transition of the double bond present in the rGO sheets, similarly the peak at $313 \mathrm{~nm}$ corresponds to the $\mathrm{n}$ to $\pi^{*}$ electronic transition of $\mathrm{C}=\mathrm{O}$ groups remained even after the reduction of the functional groups present over GO. Both the peaks however underwent red shifting in the present case compared to the expected positions ${ }^{43}$. The AgNPs-rGO composite also showed peaks at 252 and $313 \mathrm{~nm}$, indicating the presence of rGO in the composite. The peak at $438 \mathrm{~nm}$ corresponds to the surface plasmon band of the AgNPs, confirms the presence of AgNPs in the composite material. ${ }^{43,44}$ The results of the FTIR measurements of GO and rGO are shown in "AgNPs-rGO" composite Fig. 1b. The peak at $1730 \mathrm{~cm}^{-1}$ in $\mathrm{GO}$ corresponds to the stretching vibration of $\mathrm{C}=\mathrm{O}$ bond, the $\mathrm{C}=\mathrm{C}$ bond produced at $1612 \mathrm{~cm}^{-1}$. The bands at $1222 \mathrm{~cm}^{-1}$ and at $1045 \mathrm{~cm}^{-1}$ correspond to the stretching bands for $\mathrm{C}-\mathrm{O}-\mathrm{C}$ bond and $\mathrm{C}-\mathrm{O}$ bond respectively. The $\mathrm{O}-\mathrm{H}$ stretching band is observed at $3400 \mathrm{~cm}^{-1}$. Significant decrease in the intensities of the bands are observed in $\mathrm{rGO}$, the $\mathrm{O}-\mathrm{H}$ stretching peak has been reduced significantly, similarly the band at $1730 \mathrm{~cm}^{-1}$ also decreased significantly. Decrease of the intensities of the bands corresponding to the positions of various functional groups in rGO indicates the successful reduction of GO to form rGO. The AgNPs-rGO composites has shown further decrease in the intensities of most of the peaks, which indicates that $\mathrm{Ag}^{+}$interacts with carbonyl groups over rGO substrate. ${ }^{43}$ These residual functional groups remained after the reduction of $\mathrm{GO}$ are beneficial in forming the composite between rGO and AgNPs. Fig. 2 demonstrates the XRD patterns of rGO, AgNPs and AgNPs deposited on rGO. The broad peak exists at $24-28^{\circ}(002)$ is ascribed to the rGO sheets restacking into an ordered crystalline structure (Fig. 2a). The Fig. 2b, shows the diffraction peaks at $38.1^{\circ}, 44.4^{\circ}, 64.8^{\circ}, 77.7^{\circ}$ and $80.1^{\circ}$ correspond to the (111), (200), (220), (311) and (222) lattice planes of the Ag nanoparticles, respectively. $^{2}$ The diffractograms of AgNPs-rGO composites exhibits peaks at $38.1^{\circ}, 44.4^{\circ}, 64.8^{\circ}, 77.7^{\circ}$ and $80.1^{\circ}$ correspond to the (111), (200), (220), (311) and (222) lattice planes of the AgNPs respectively, (Fig. 2c). ${ }^{3}$ It can be also seen from Fig. 2c, the presence of broad diffraction peak (002) at $28^{\circ}$ is due to the rGO sheets restacking into an ordered crystalline structure. The presence of highly 
intense Ag peaks and broad rGO peaks (Fig. 2c) reveals that AgNPs-rGO nanocomposite was successfully synthesized. The average particle size of the AgNPs can be calculated from the most intense (111) diffraction peak according to Scherrer's equation. The average crystallite size was found to be about $32.34 \mathrm{~nm}$.
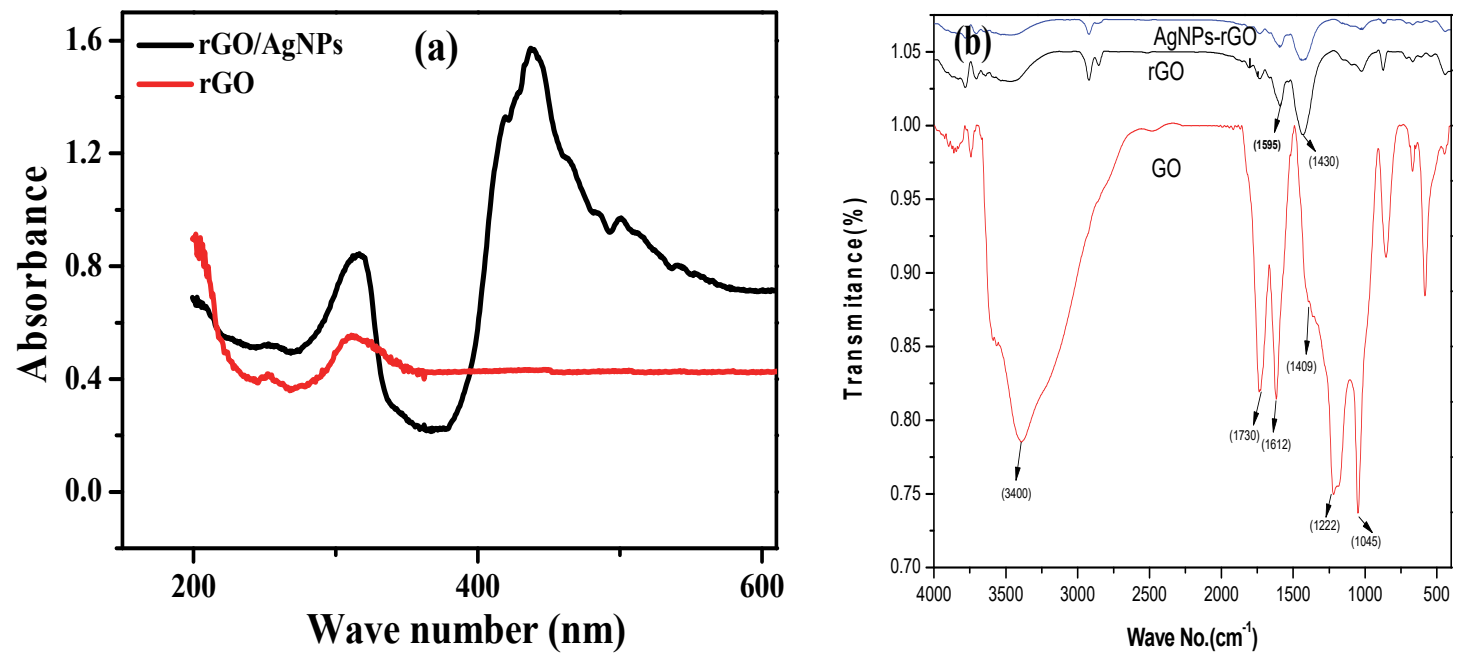

Fig. 1. (a) The reflectance spectra of rGO and AgNPs-rGO composite (b) FTIR spectra of GO, rGO and AgNPs-rGO
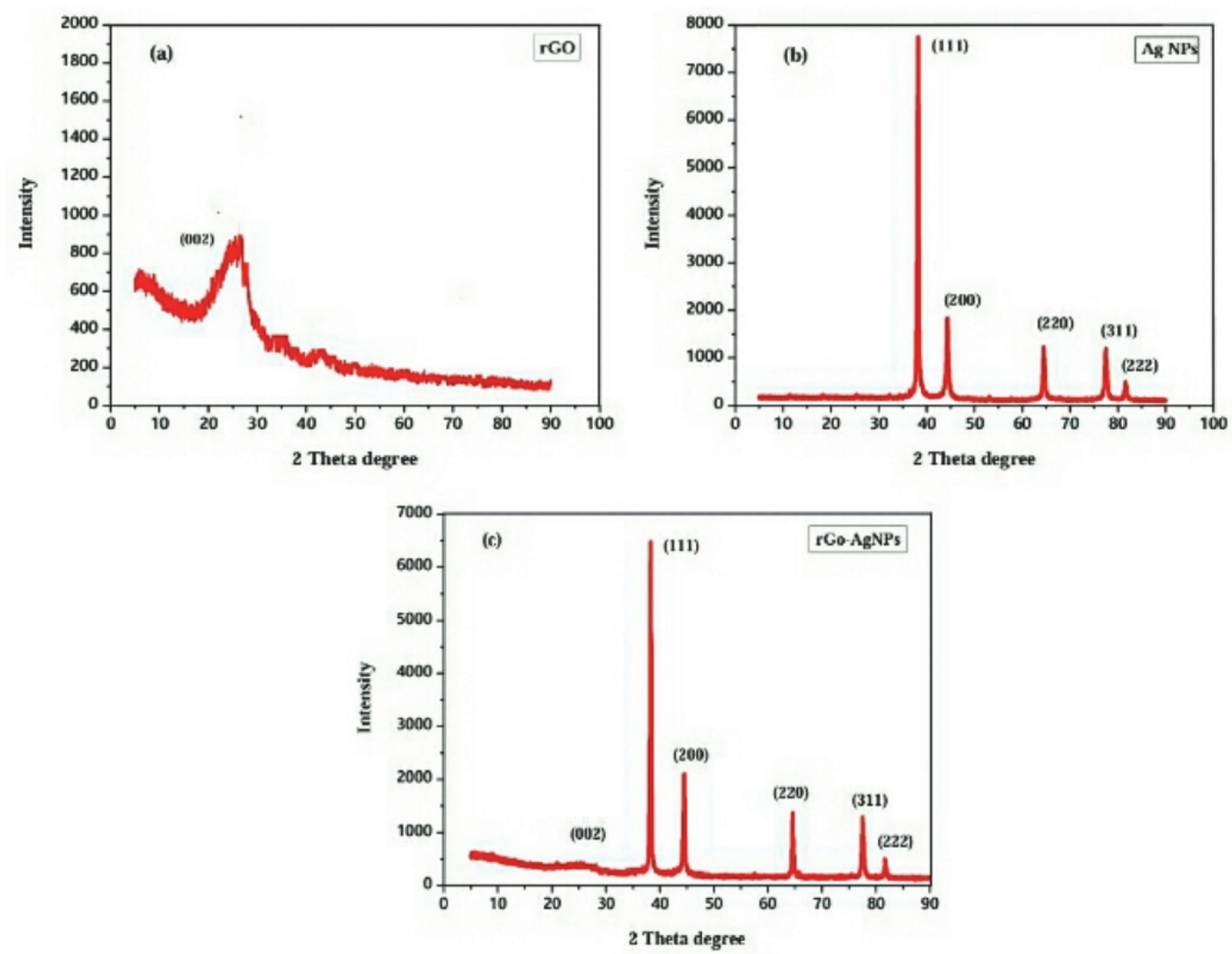

Fig. 2. X-ray diffraction (XRD) Patterns of (a) rGO (b) AgNPs and (c) AgNPs-rGO composite 
In order to obtain information about the morphological properties of the synthesized materials, some essential characterizations were conducted. The morphology of the AgNPs-rGO nanocomposite was examined by SEM and FE-SEM techniques. Fig. 3a and Fig. 3b shows the SEM and FE-SEM images of AgNPs deposited on the rGO support using a metal to metal reduction method. SEM images showed that AgNPs are of spherical shape and highly dispersed on rGO support. From Fig. 3a, it can be seen that the AgNPs are evenly supported on the surface of rGO without apparent aggregation. The morphology of AgNPs-rGO nanocomposite is much diversified, ranging from nanoparticles to nanorods and nanoplates (Fig. 3b). Fig. 3b, exhibits plate-like structures with some aggregation of the silver nanosheets deposited on the rGO surface.

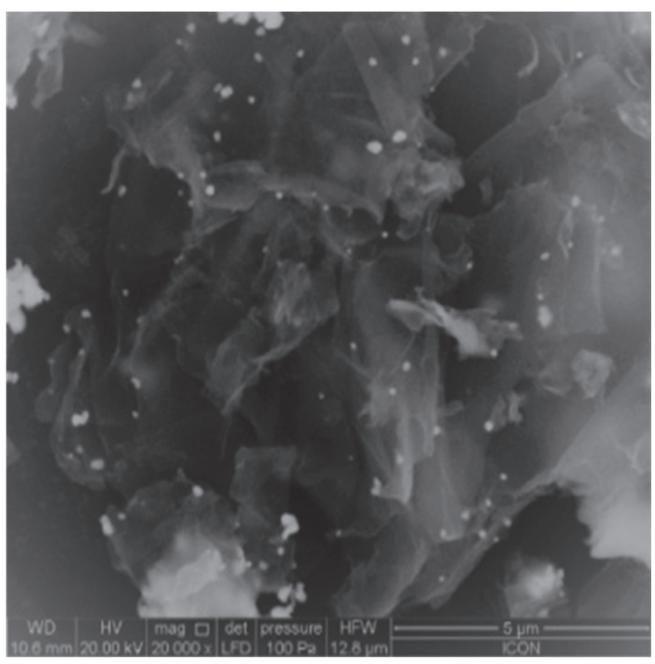

(a)

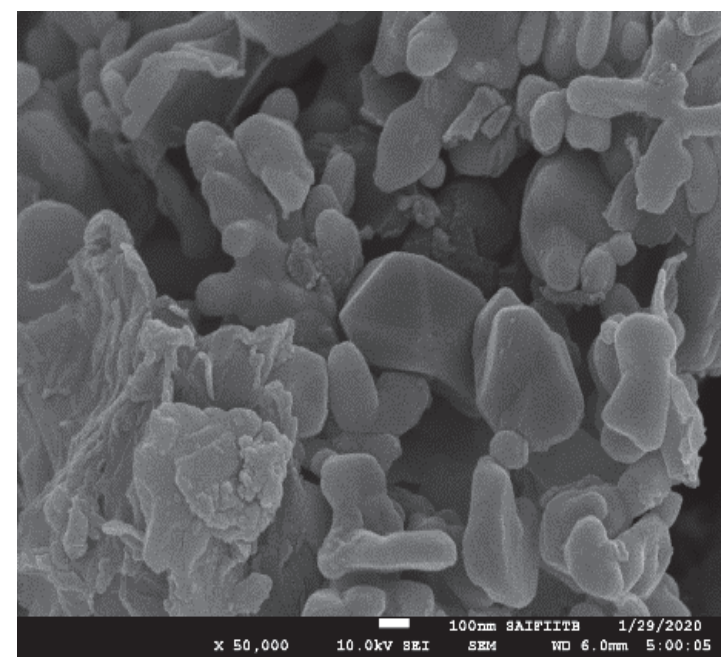

(b)

Fig. 3. (a) SEM image and (b) FE-SEM of AgNPs-rGO nanocomposite

\subsection{Electrochemical Behaviour of Modified Electrodes}

Fig. 4 shows the cyclic voltammograms of bare GCE, rGO/GCE and AgNPs-rGO/GCE modified electrodes without (a) in $0.1 \mathrm{M}$ PBS (pH 7.0) and with (b) $5 \mathrm{mM} \mathrm{H}_{2} \mathrm{O}_{2}$. Fig. 4a, compares the cyclic voltammograms bare GCE, rGO/GCE and AgNPs-rGO/GCE modified electrodes in $0.1 \mathrm{M}$ PBS. No obvious redox peaks are observed for the bare and rGO modified electrodes. However, two distinct redox peaks at the anodic peak potential of $0.46 \mathrm{~V}$ and the cathodic peak potential at $0.05 \mathrm{~V}$ are observed for AgNPs-rGO/GCE modified electrodes. The peaks correspond to the one-electron redox process of Ag nanoparticles. ${ }^{2}$ Fig. $\mathbf{4 b}$, shows the electrochemical response of $\mathrm{H}_{2} \mathrm{O}_{2}$ over AgNPs$\mathrm{rGO} / \mathrm{GCE}, \mathrm{rGO} / \mathrm{GCE}$ and bare GCE electrodes. The AgNPs-rGO/GCE showed significantly higher electrocatalytic activity than $\mathrm{rGO} / \mathrm{GCE}$. Bare GCE does not produce any significant current for the reduction of $\mathrm{H}_{2} \mathrm{O}_{2}$. As seen from Fig. $4 \mathbf{b}$, in presence of $\mathrm{H}_{2} \mathrm{O}_{2}$, the reduction peak current increased indicating that AgNPs-rGO/GCE can be used as the sensor for the electrocatalytic determination of $\mathrm{H}_{2} \mathrm{O}_{2}$. Since the electrochemical response is improved in the presence of both AgNPs and rGO, the overall improved catalytic current of AgNPs-rGO/GCE resulted due to the synergestic effect of both AgNPs and rGO. The small particle size of AgNPs with high charge density would have a significant contribution towards the reduction of $\mathrm{H}_{2} \mathrm{O}_{2}$. After addition of $\mathrm{H}_{2} \mathrm{O}_{2}$ to the solution, the small particle size of AgNPs with high charge density would have significant contribution towards the reduction of $\mathrm{H}_{2} \mathrm{O}_{2}$. After addition of $\mathrm{H}_{2} \mathrm{O}_{2}$ to the solution, AgNPs are entangled over the surface of the rGO, catalyse the reduction of $\mathrm{H}_{2} \mathrm{O}_{2}$ to form the reactive oxygen species $\mathrm{O}^{-2}$, further on application of reduction potential during the potential scan, $\operatorname{Ag}(\mathrm{I})$ is reduced back to the $\operatorname{Ag}(0)$ nanoparticles and the reactive oxygen species is reduced to water, the mechanism of the process has been symmetrised in the equations as below. ${ }^{5,45,55}$. 


$$
\begin{aligned}
& \mathrm{Ag}(0) \mathrm{NPs}-\mathrm{rGO}+\mathrm{H}_{2} \mathrm{O}_{2} \rightarrow \mathrm{Ag}(\mathrm{I}) \mathrm{NPs}-\mathrm{rGO}+\mathrm{O}^{-2}+2 \mathrm{H}^{+} \\
& \mathrm{Ag}(\mathrm{I}) \mathrm{NPs}-\mathrm{rGO}+\mathrm{O}^{-2}+2 \mathrm{H}^{+}+2 \mathrm{e}^{-} \rightarrow \mathrm{Ag}(0) \mathrm{NPs}-\mathrm{rGO}+\mathrm{H}_{2} \mathrm{O}
\end{aligned}
$$
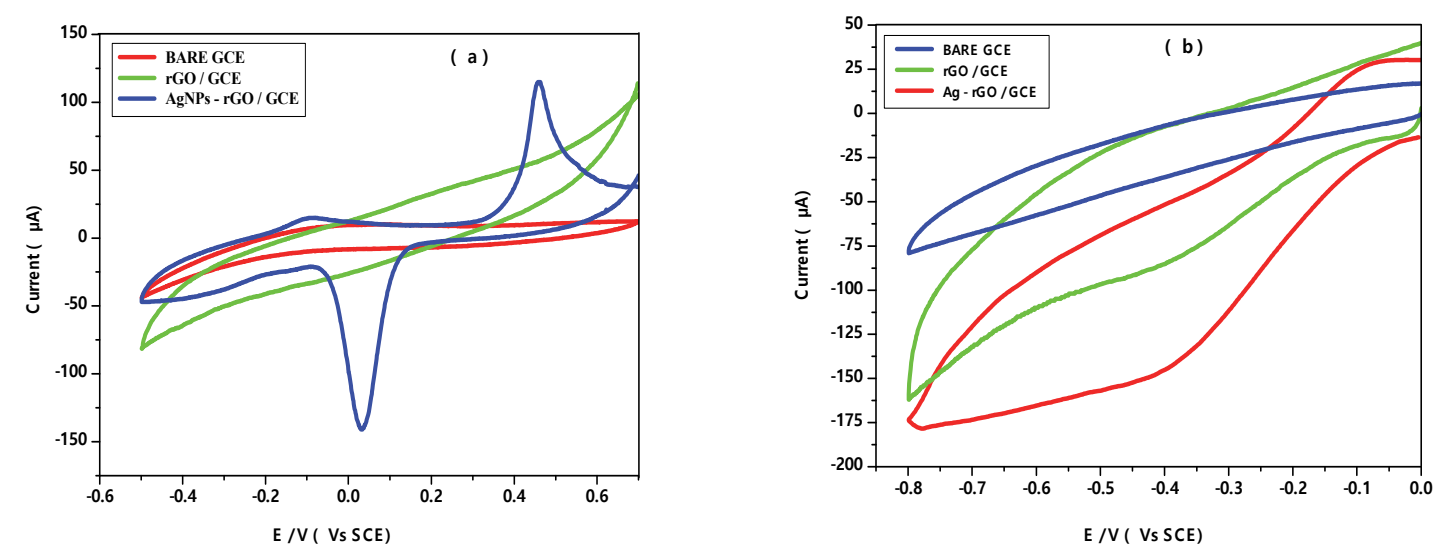

Fig. 4. (a) Cyclic voltammograms of bare GCE, rGO/GCE and AgNPs-rGO/GCE in $0.1 \mathrm{M} P B S$ (pH 7.0), (b) Cyclic voltammograms of bare GCE, rGO/GCE and AgNPs-rGO/GCE modified electrode in $0.1 \mathrm{M}$ PBS (pH 7.0) and $5 \mathrm{mM}$ $\mathrm{H}_{2} \mathrm{O}_{2}$ saturated with $\mathrm{N}_{2}$ at scan rate $50 \mathrm{mVs}^{-1}$

\subsection{Effect of scan rate on the measurements}

As shown in Fig. 5a, with the increase of scanning rate from 10 to $200 \mathrm{mVs}^{-1}, \mathrm{H}_{2} \mathrm{O}_{2}$ reduction current gradually increases, it showed a good linear relationship between the current response and the square root of the scan rate (Fig. 5b), with linear correlation coefficient $R=0.9979$. This indicates that the reduction of $\mathrm{H}_{2} \mathrm{O}_{2}$ on the AgNPs-rGO modified GCE surface is a diffusion control process.

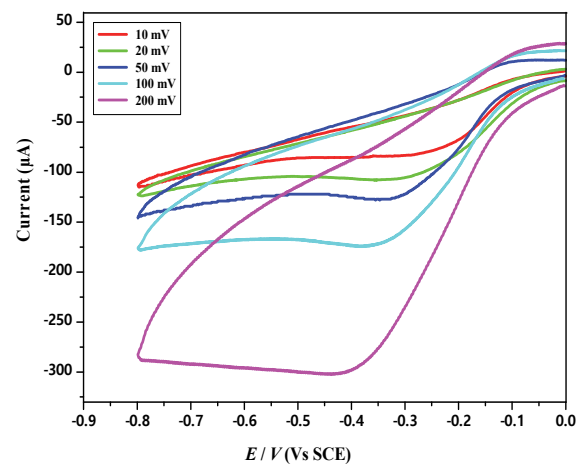

(a)

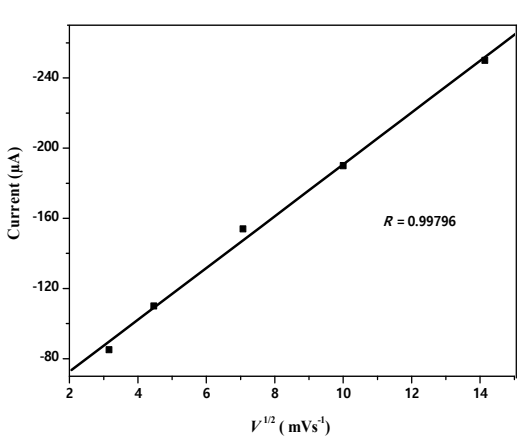

(b)

Fig. 5. (a) Cyclic voltammograms of AgNPs-rGO/GCE in $0.1 \mathrm{M} P B S$ (pH 7.0) saturated with $5 \mathrm{mM} \mathrm{H}_{2} \mathrm{O}_{2} \mathrm{~N}_{2}$ at different scan rates from 10, 20, 50, 100, $200 \mathrm{mVs}^{-1}$ respectively (b) The plot of peak current versus the square root of scan rate.

\subsection{Electrochemical behaviour of $\left[\mathrm{Fe}(\mathrm{CN})_{6}\right]^{-3 / 4}$ couple at AgNPs-rGO nanocomposite modified electrode}

The electroactive surface area of electrodes was determined by recording CVs of bare, rGO and

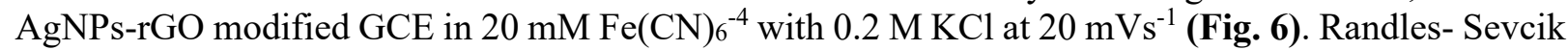
equation was used to calculate the electroactive surface area of the electrode.

$I p=2.69 \times 10^{5} \times A \times D^{1 / 2} \times n^{3 / 2} \times v^{1 / 2} \times C$. 
where $(A)$ is the area of the electrode $\left(\mathrm{cm}^{2}\right),(D)$ is diffusion coefficient of the molecule $\left(\mathrm{cm}^{2} / \mathrm{s}\right),(\mathrm{n})$ is number of electron transfer in the redox reaction, $(v)$ is scan rate $(\mathrm{V} / \mathrm{s})$ and $(C)$ is concentration of the analyte solution $(\mathrm{mM})$, respectively. $\mathrm{In} \mathrm{Fe}(\mathrm{CN}) 6^{-4 /-3}$ redox system, the value of $D$ is equal to $6.7 \times 10^{-6}$, the $n$ is equal to 1 , the $v$ is equal to 0.02 and the $C$ is equal to $10 \mathrm{mM}$. The electroactive surface area (ECSA) of bare, rGO and AgNPs-rGO was calculated as $0.0406 \mathrm{~cm}^{2}, 0.0650 \mathrm{~cm}^{2}$, and $0.0864 \mathrm{~cm}^{2}$, respectively and the results indicates improved electrochemical activity over the modification of bare GCE with the modifications by rGO and AgNPs-rGO.

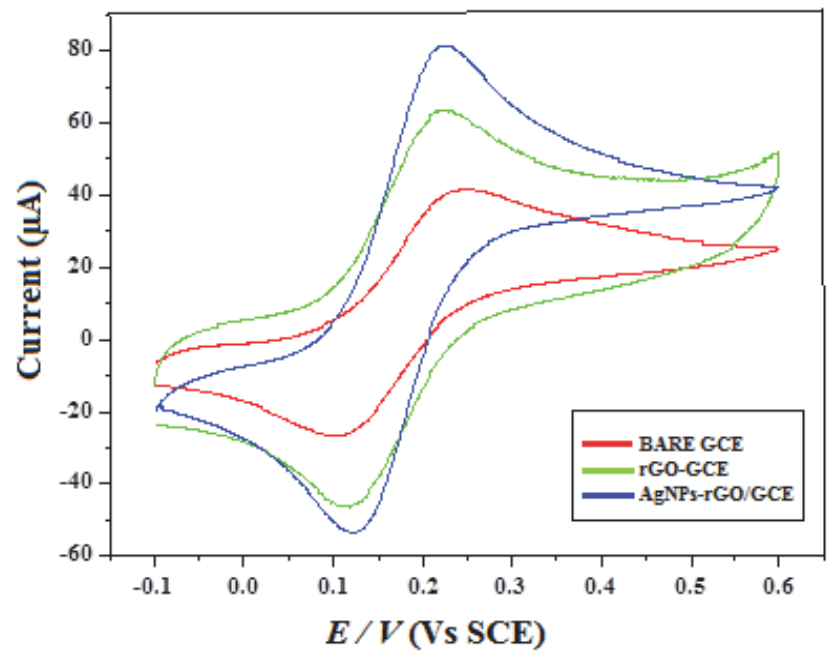

Fig. 6. Cyclic voltammograms of Bare, $\mathrm{rGO} / \mathrm{GCE}$ and $\mathrm{AgNPs}-\mathrm{rGO} / \mathrm{GCE}$ in $10 \mathrm{mM} \mathrm{Fe}(\mathrm{CN})_{6}^{-4}$ with $0.2 \mathrm{M} \mathrm{KCl}$ solution, scan rate $20 \mathrm{mVs}^{-1}$

\subsection{Electrochemical impedance spectroscopy of AgNPs-rGO nanocomposite}

The interfacial charge transfer property of the AgNPs-rGO composite material was studied using electrochemical impedance spectroscopy (EIS). The semicircle portion of the Nyquist plot signifies the ionic conducting of the materials $\left(R_{c t}\right)$ and it is observed in the high frequency range and the linear portion implies the diffusion limiting process and observed at the low frequency range. In the present study, EIS investigation was carried out to evaluate the qualitative evaluation of electronic property of the modified electrodes and the experiment was carried out using potassium ferrocyanide $(20 \mathrm{mM})$ as a redox probe at constant applied potential $0.28 \mathrm{~V}$ and the frequency range from the $0.01 \mathrm{~Hz}$ to $50 \mathrm{KHz}$ and amplitude $10 \mathrm{mV}$. Fig. 7 shows the Nyquist plot of the three electrodes, it was observed that the charge transfer resistance $\left(R_{c t}\right)$ of AgNPs-rGO was lower compared to rGO and bare GCE. Reduced graphene oxide showed lower charge transfer resistance $\left(R_{c t}\right)$ compared to bare GCE because rGO exhibited higher electrical conductivity than bare GCE. The significant decrease in the charge transfer resistance of the AgNPs-rGO composite material indicated that the improvement in the electrochemical oxidation of the redox probe due the substitution of Ag nanoparticles. ${ }^{46-47} \mathrm{In}$ addition to the decrease in the charge transfer resistance, strong presence of the Warburg component is observed in case of AgNPs-rGO/GCE, which indicates the applied potential during EIS measurement is sufficient to satisfy the activation requirements and the electrochemical reduction process of $\mathrm{H}_{2} \mathrm{O}_{2}$ follows the diffusion control in nature. The EIS results thus confirm that the AgNPs-rGO composite could be used as suitable electrode material for the non-enzymatic detection of the $\mathrm{H}_{2} \mathrm{O}_{2}$.

\subsection{Amperometric detection of $\mathrm{H}_{2} \mathrm{O}_{2}$ at modified $\mathrm{AgNPs}-\mathrm{rGO}$ electrode}

Fig. 8a, shows the amperometric current-time response curve for AgNPs-rGO/GCE in $\mathrm{N}_{2}$ saturated PBS ( $\mathrm{pH}$ 7.0) solution for successive addition of $\mathrm{H}_{2} \mathrm{O}_{2}$ at constant potential of $-0.4 \mathrm{~V}$. It was observed that the current response to successive addition of $\mathrm{H}_{2} \mathrm{O}_{2}$ is increases proportionately. Furthermore, after 
every successive addition of $\mathrm{H}_{2} \mathrm{O}_{2}$, AgNPs-rGO/GCE rapidly responds to hydrogen peroxide and the reduction current significantly increases and reaches to a steady state within $5 \mathrm{~s}$. Fig. $8 \mathbf{b}$, shows a linear relation between the reduction current and the concentration of $\mathrm{H}_{2} \mathrm{O}_{2}$ with a linear range of $1.5 \mu \mathrm{M}$ to $100 \mathrm{mM}$. The correlation coefficient for the linear correlation using the AgNPs-rGO/GCE was obtained as 0.994 . The sensitivity of $\mathrm{H}_{2} \mathrm{O}_{2}$ modified sensor was $12.73 \mu \mathrm{A} \cdot \mathrm{cm}^{-2} \cdot \mathrm{mM}^{-1}$ of $\mathrm{H}_{2} \mathrm{O}_{2}$, the limit of quantification (LOQ) of AgNPs-rGO coated GC electrode $6.35 \mu \mathrm{M}$ and the detection limit $1.90 \mu \mathrm{M}$ estimated at a signal to noise ratio of $3(S / N=3)$.

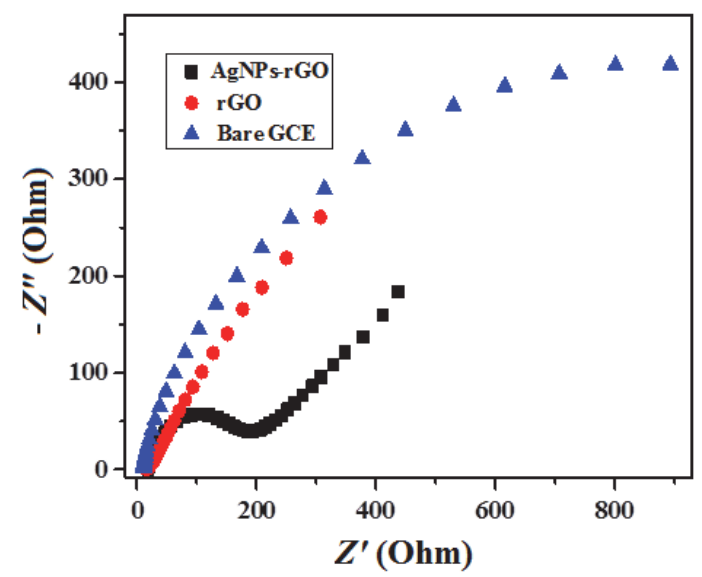

Fig. 7. Nyquist plots obtained for $20 \mathrm{mM}$ of $\mathrm{K}_{3}\left[\mathrm{Fe}(\mathrm{CN})_{6}\right]$ in $0.2 \mathrm{M} \mathrm{KCl}$ at bare $\mathrm{GCE}, \mathrm{rGO} / \mathrm{GCE}$ and $\mathrm{AgNPs}-\mathrm{rGO} / \mathrm{GCE}$

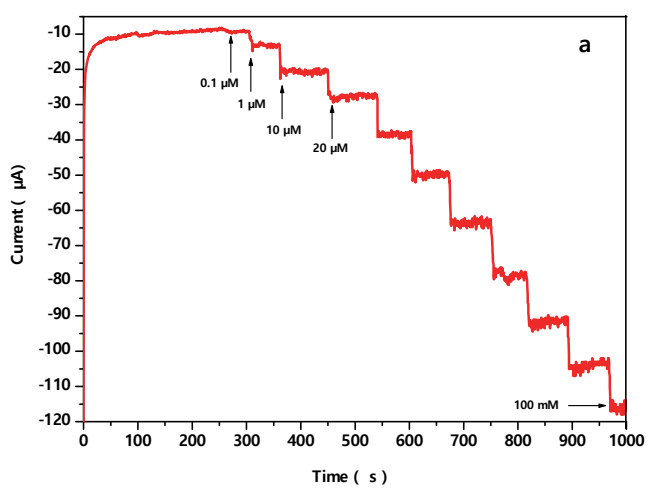

(a)

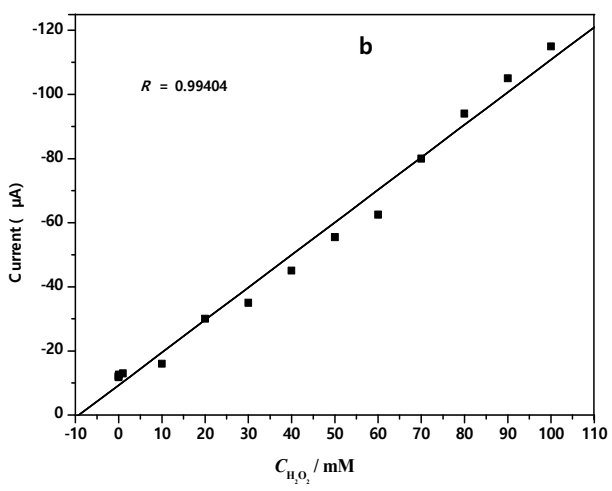

(b)

Fig. 8. (a) Steady-state response of the AgNPs-rGO/GCE for successive addition of $\mathrm{H}_{2} \mathrm{O}_{2}$ in the stirred $0.1 \mathrm{M} P B S$ (pH 7) saturated with $\mathrm{N}_{2}$ at an applied potential of $-0.4 \mathrm{~V}$. (b) calibration curve at a concentration range of $0.1 \mu \mathrm{m}-100 \mathrm{mM}$

\subsection{Interference study and real sample analysis}

Fig. 9 demonstrates the amperometric response of the AgNPs-rGO/GCE for the consecutive addition of $\mathrm{H}_{2} \mathrm{O}_{2}(10 \mathrm{mM}$ ) and Ascorbic acid (AA), Glucose (Glu) and Uric acid (UA) (50 and $100 \mathrm{mM}$ each) in $\mathrm{N}_{2}$ saturated 0.1 M PBS (pH 7) at $-0.4 \mathrm{~V}$. However, AgNPs-rGO/GCE exhibited considerable current response to $\mathrm{H}_{2} \mathrm{O}_{2}$, signifying that the modified GCE with AgNPs-rGO has good selectivity for $\mathrm{H}_{2} \mathrm{O}_{2}$ and good anti-interference capacity to the electroactive substances investigated. These excellent properties of AgNPs-rGO made the sensor suitable for practical applications in sensing $\mathrm{H}_{2} \mathrm{O}_{2}$. To study the application of the modified sensor, a groundwater sample was used for performing the detection of $\mathrm{H}_{2} \mathrm{O}_{2}$ (Table 1). The determination of $\mathrm{H}_{2} \mathrm{O}_{2}$ in the mentioned samples solution was carried out at modified sensor by employing standard addition method. The sample was diluted by using $0.1 \mathrm{M}$ PBS (pH 7.0). Later, $\mathrm{H}_{2} \mathrm{O}_{2}$ solution was successively added to the sample solution to measure the current 
response by using standard addition method. All the measurements were carried out three times. Table 1 shows the average recoveries of all the measurements. From the above results, it can be concluded that the fabricated sensor holds practical applications for the determination of definite concentration of $\mathrm{H}_{2} \mathrm{O}_{2}$ in routine sample analysis.

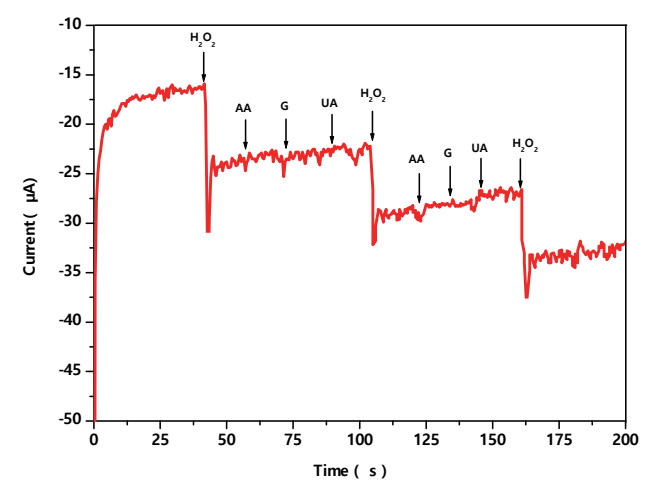

Fig. 9. Amperometric response of AgNPs-rGO/GCE for the successive addition of $10 \mathrm{mM} \mathrm{H}_{2} \mathrm{O}_{2}$ and 50 and $100 \mathrm{mM}$ ascorbic acid, glucose and uric acid into $0.1 \mathrm{M}$ PBS ( $\mathrm{pH} 7)$ saturated with $\mathrm{N}_{2}$ at an applied potential $-0.4 \mathrm{~V}$ under stirring condition.

Table 1. Determination of $\mathrm{H}_{2} \mathrm{O}_{2}$ in real Sample

\begin{tabular}{cccccc}
\hline Sample & Added $(\mathbf{m M})$ & SD & RSD \% & Measured $(\mathbf{m M})$ & Recovery \% \\
\hline 1 & 0.1 & 0.000811 & 0.810 & 0.096 & 96.00 \\
2 & 1.0 & 0.02085 & 1.655 & 0.974 & 97.40 \\
3 & 5.0 & 0.2948 & 6.296 & 5.029 & 100.58 \\
\hline
\end{tabular}

\subsection{Repeatability, reproducibility and stability}

The reproducibility of AgNPs-rGO modified GCE electrode was examined in the presence of 5.0 $\mathrm{mM} \mathrm{H}_{2} \mathrm{O}_{2}$ in $0.1 \mathrm{M}$ PBS ( $\mathrm{pH} 7$ ) at $\mathrm{N}_{2}$ saturated condition for five successive modifications of GCE with the relative standard deviation (RSD) of about $2.6 \%$. Furthermore, the repeatability of the sensor was obtained from the repetitive measurements of $5.0 \mathrm{mM} \mathrm{H}_{2} \mathrm{O}_{2}$ solution. It was found that the RSD of current responses of one modified GCE for five successive measurements was found to be less than $4 \%$, suggesting that the modified electrode had high repeatability. Moreover, the current response of the modified sensor decreased to $91.2 \%$ of its original value after being stored in the refrigerator at 4 ${ }^{\circ} \mathrm{C}$ for 10 days. The above results indicated the reliability and long-term stability of the fabricated $\mathrm{H}_{2} \mathrm{O}_{2}$ sensor.

\subsection{Comparison of Electrocatalytic performance of AgNPs-rGO modified electrode}

Results obtained in this study are compared with the results reported in the literature and placed in (Table 2). It was found that the composite materials modified electrode developed in the present investigation has higher electrocatalytic activity for the hydrogen peroxide determination. Compared with other studies, the sensor exhibits wide linear range, low detection limit and high sensitivity.

\section{Conclusions}

In summary, a nanocomposite of AgNPs-rGO was successfully synthesized via facile and green method. The XRD analysis confirmed the formation of rGO and AgNPs-rGO nanocomposite. Further, SEM and FE-SEM analysis showed uniform deposition of AgNPs on rGO sheets with small particle size. The AgNPs-rGO/GCE fabricated sensor exhibited excellent electrocatalytic activity towards $\mathrm{H}_{2} \mathrm{O}_{2}$ reduction. The modified $\mathrm{H}_{2} \mathrm{O}_{2}$ sensor showed a rapid response to $\mathrm{H}_{2} \mathrm{O}_{2}$ concentration variation at an optimized working potential of $-0.4 \mathrm{~V}$. In addition, the modified $\mathrm{H}_{2} \mathrm{O}_{2}$ sensor exhibited high selectivity 
over interfering species such as uric acid (UA), ascorbic acid (AA) and glucose. The combined effect due to the electrocatalytic reduction from the AgNPs with good conductivity and improved surface area from the rGO has generated positive synergistic effect in the overall improvement in the reduction process of hydrogen peroxide, leading to better sensitivity. It is concluded that the present work confirms a low cost, simple, one-step and environment friendly protocol for the preparation of AgNPs$\mathrm{rGO} / \mathrm{GCE}$ nanocomposite, which works as an effective non-enzyme electrochemical $\mathrm{H}_{2} \mathrm{O}_{2}$ sensor.

Table 2. Comparison of Electrocatalytic performance of AgNPs-rGO modified electrode.

\begin{tabular}{|c|c|c|c|c|c|c|}
\hline Sensors & $\begin{array}{l}\text { Applied } \\
\text { potential } \\
\text { (V) }\end{array}$ & $\begin{array}{l}\text { Linear range } \\
\quad(\mathrm{mM})\end{array}$ & $\begin{array}{c}\text { Detection } \\
\text { Limit }(\mu \mathrm{M})\end{array}$ & $\begin{array}{c}\text { Sensitivity } \\
\mu \text { A.m.m } \mathbf{M}^{-1} \cdot \mathbf{c m}^{-2}\end{array}$ & Detection Method & Ref. \\
\hline $\mathrm{Ag}-\mathrm{AuNPs} / \mathrm{rGO}$ & -0.2 & $0.1-10$ & 0.57 & 112.05 & Amperometric & $\lceil 2\rceil$ \\
\hline Porous Ag & -0.2 & $0.5-4.5$ & 29.8 & 31.8 & Amperometric & {$[48]$} \\
\hline AuNPs-GO/Pt & 0.4 & $0.05-4.6$ & $0.025 \mathrm{mM}$ & 31.47 & Amperometric & [49] \\
\hline AgNPs-NFs/GCE & -0.48 & $100 \mu \mathrm{M}-80 \mathrm{mM}$ & 65.0 & ---- & Amperometric & {$[50]$} \\
\hline APS(SG)-AgNPs & -0.5 & $100 \mu \mathrm{M}-1 \mathrm{mM}$ & 25.0 & $0.042 \mu \mathrm{A} / \mu \mathrm{M}$ & Amperometric & [51] \\
\hline AgNPs@,GQDs/Cs & -0.5 & $0.1-10$ & $0.10 \mathrm{mM}$ & --- & Amperometric & {$[52]$} \\
\hline CS/AgNPs & -0.7 & $0.1-1.0$ & 50.0 & ---- & Amperometric & [53] \\
\hline AgNPs/GQD & --- & $0.5-50 \mu \mathrm{M}$ & $162 \mathrm{nM}$ & ---- & Colorimetric & {$[54]$} \\
\hline Ti:CdO/ITO & & $10-170 \mu \mathrm{M}$ & 4 & $0.27 \mu \mathrm{A} . \mu \mathrm{M}^{-1} \mathrm{~cm}^{-2}$ & Amperometric & {$[55]$} \\
\hline Ag-Au-rGO & -0.4 & $0.1-5$ & 1 & ---- & Amperometric & {$[56]$} \\
\hline $\mathrm{NGNF} / \mathrm{MnO}_{2}$ & -0.6 & $0.1-11$ & 1.25 & 1096 & Amperometric & [57] \\
\hline $\mathrm{CoFe}_{2} \mathrm{O}_{4} \mathrm{HS} / \mathrm{GCE}$ & -0.45 & $0.01-1.2$ & 2.5 & $17 \mathrm{nA} \mu \mathrm{M}^{-1} \mathrm{~cm}^{-2}$ & Amperometric & {$[58]$} \\
\hline $\mathrm{rGO} / \mathrm{CuFe}_{2} \mathrm{O}_{4} / \mathrm{GCE}$ & -0.4 & $1 \mu \mathrm{M}-11 \mathrm{mM}$ & 0.35 & 265.57 & Amperometric & $\lceil 59\rceil$ \\
\hline AgNPs-rGO & -0.4 & $0.0015-100$ & 1.90 & 12.73 & Amperometric & $\begin{array}{l}\text { This } \\
\text { Work }\end{array}$ \\
\hline
\end{tabular}

\section{Acknowledgements}

The authors are thankful to SAIF and Department of Energy Sciences and Engineering IIT, Mumbai for FE-SEM and XRD analysis.

\section{Experimental}

\subsection{Materials and Methods}

Graphite fine powder (98\%, LR) was purchased from Molychem (India). Sulphuric acid $\left(\mathrm{H}_{2} \mathrm{SO}_{4}\right.$, 98\%, AR) S.D. Fine ltd. (India), Potassium Permanganate $\left(\mathrm{KMnO}_{4}, 99 \%\right.$, AR) purchased from Qualigens Fine Chemicals (India), Sodium Hydroxide pellets ( $\mathrm{NaOH}, 98 \%$, AR) SD Fine-chem ltd.(India), Hydrogen Peroxide $\left(\mathrm{H}_{2} \mathrm{O}_{2} 30 \%\right.$, AR) Thomas Baker (India), Disodium Hydrogen Phosphate Dibasic Dihydrate $\left(\mathrm{Na}_{2} \mathrm{HPO}_{4} \cdot 2 \mathrm{H}_{2} \mathrm{O}\right)$, Sodium Dihydrogen Phosphate Monobasic $\left(\mathrm{NaH}_{2} \mathrm{PO} 4\right)$, LAscorbic Acid (98\%, AR), Silver nitrate ( $\mathrm{AgNO}_{3}$ 99\%, AR) and copper metal foil purchased from SD fine-chem industry (India). All the chemicals and reagents were Analytical grade and used without any further purification. All samples and other aqueous solutions were prepared in double distilled water.

The structural characterization of the samples was carried out by using X-ray powder diffractometer (XRD; Rigaku, Smart Lab, Japanusing $\mathrm{CuK} \alpha$ radiation). The morphological and elemental composition study was carried by using Field Emission Gun scanning electron microscope equipped with EDX (FEG-SEM, JSM-7600F operated at $10.0 \mathrm{kV}$ ) and Ultrasonicator (Oscar Ultrasonic Microclean-103). Ultraviolet-Visible and Infrared spectroscopy (UV and IR) measurements were carried out using a QE65000 detector from Ocean Optics attached with a reflectance probe. FTIR measurements are 
carried out using the Tenser II spectrometer from Bruker. Electrochemical measurements were carried out at DY2300 Series Potentiostat electrochemical workstation (Austin, TX, USA) with three electrode system consists of a bare or modified glassy carbon electrode ( $\mathrm{GCE}, \mathrm{d}=2.0 \mathrm{~mm}$ ) as working electrode, a platinum foil $(1 \times 1 \mathrm{~cm})$ as a counter electrode and a saturated calomel electrode (SCE) was served as a reference electrode. The Cyclic voltamograms were recorded in the potential range from -0.5 to 0.7 $\mathrm{V}$ in $0.1 \mathrm{M}$ phosphate buffer solution ( $\mathrm{pH} 7.0$ ) with scan rate of $50 \mathrm{mVs}^{-1}$. All potential values included in this paper were used against the SCE. Electrochemical impedance spectroscopy (EIS) measurements were carried using the PGSTAT 302N from Autolab.

\subsection{General procedure}

\subsubsection{Synthesis of $r G O$}

The rGO was prepared from natural graphite powder according to the reported method. ${ }^{22} 1 \mathrm{~g}$ of graphite flakes was transferred to the beaker containing $50 \mathrm{~mL}$ concentrated sulphuric acid with constant stirring in an ice cooled water bath. Then $3 \mathrm{~g}$ potassium permanganate was slowly added at controlled temperature below $10{ }^{\circ} \mathrm{C}$. After this the suspension was stirred at room temperature for 25 $\mathrm{min}$. Then suspension was sonicated for $5 \mathrm{~min}$ in an ultrasonic bath. The stirring-sonication process was repeated for 12 times. Then reaction mixture was quenched by $200 \mathrm{~mL}$ distilled water. The suspension was ultrasonicated for $2 \mathrm{~h}$. The suspension was divided into two parts: one part is used for rGO preparation and the other part was washed with $\mathrm{HCl}$ and distilled water. Finally centrifuged and dried at room temperature to obtain GO. The $\mathrm{pH}$ of second part of the suspension was adjusted to around 6 by the addition of $1 \mathrm{M}$ sodium hydroxide solution, the suspension was further sonicated for 1 h. $100 \mathrm{~mL}$ of L-ascorbic acid (10\%) was slowly added to the graphite oxide suspension at room temperature. The reduction was carried out at $95^{\circ} \mathrm{C}$ for $1 \mathrm{~h}$. The resultant black precipitate was filtered through Whatman No. 41 filter paper and washed with a $1 \mathrm{M}$ hydrochloric acid solution and distilled water to neutral $\mathrm{pH}$. The rGO powder was obtained after drying the residue.

\subsubsection{Synthesis of (AgNPs-rGO) composite}

$100 \mathrm{mg}$ of previously synthesized rGO was dispersed in $100 \mathrm{~cm}^{3}$ of $10 \mathrm{mM} \mathrm{AgNO} 3$ solution (1 $\mathrm{mg} / \mathrm{mL}$ ) by ultrasonication for $1 \mathrm{~h}$. To this $\mathrm{rGO}-\mathrm{AgNO}_{3}$ aqueous suspension, a pure, thin copper metal foil $(1 \times 5 \mathrm{~cm})$ was immersed and kept under continuous stirring for $1 \mathrm{~h}$ at room temperature. After $1 \mathrm{~h}$, AgNPs were formed and deposited on the surface of $\mathrm{rGO}$ via reduction of $\mathrm{Ag}^{+}$by copper metal. After the completion of redox reaction, (AgNPs-rGO) nanocomposite suspension was separated by centrifugation and washed with distilled water and finally with ethanol. The prepared nanocomposite then dried at $60{ }^{\circ} \mathrm{C}$.

\subsubsection{Fabrication of the $\mathrm{H}_{2} \mathrm{O}_{2}$ sensor}

A Glassy Carbon electrode (GCE, $\mathrm{d}=2 \mathrm{~mm}$ ) was polished with 0.3 and $0.05 \mu \mathrm{m}$ alumina and water slurry, followed by rinsing with ethanol, distilled water and then dried in air. After that, $1 \mathrm{mg}$ of (AgNPs-rGO) nanocomposite was dispersed in $1 \mathrm{ml}$ of doubled distilled water under ultrasonication for $10 \mathrm{~min}$. Then, for the modification of GCE, $5 \mu \mathrm{L}(1 \mathrm{mg} / \mathrm{mL})$ of this aqueous suspension was dropped on the surface of a cleaned GCE and dried in air at room temperature. This modified GCE is used for further electrochemical work as a working electrode $\left(\mathrm{H}_{2} \mathrm{O}_{2}\right.$ sensor).

\section{References}

1. Mahaseth T., Kuzminov A (2017) Potentiation of Hydrogen Peroxide Toxicity From Catalase Inhibition to Stable DNA-iron Complexes. Mutat Res., 773 274-281. 
2. Zhao L., Wang Y., Zhao X., Deng Y., Li Q., Xia Y (2018) Green Preparation of Ag-Au Bimetallic Nanoparticles Supported on Graphene with Alginate for Non-Enzymatic Hydrogen Peroxide Detection. Nanomaterials, 8 (7) 507.

3. Fu L., Lai G., Jia B., Yu A (2015) Preparation and Electrocatalytic Properties of Polydopamine Functionalized Reduced Graphene Oxide-Silver Nanocomposite. Electrocatalysis, 6 (1) 72-76.

4. Noor AM., Shahid MM., Rameshkumar P., Huang NM (2016) A glassy carbon electrode modified with graphene oxide and silver nanoparticles for amperometric determination of hydrogen peroxide. Microchim Acta, 183 (2) 911-916.

5. Nia PM., Meng WP., Alias Y (2015) Hydrogen peroxide sensor: Uniformly decorated silver nanoparticles on polypyrrole for wide detection range. Applied Surface Science, 357-B 1565-1572.

6. Li X., Liu Y., Zheng L., Dong M., Xue Z., Lu X., Liu X (2013) A novel nonenzymatic hydrogen peroxide sensor based on silver nanoparticles and ionic liquid functionalized multiwalled carbonnanotube composite modified electrode. Electrochimica Acta, 113 170-175.

7. Hurdis EC., Romeyn H (1954) Accuracy of determination of hydrogen peroxide by cerate oxidimetry. Anal. Chem., 26 (2) 320-325.

8. Abo M., Urano Y., Hanaoka K., Terai T., Komatsu T., Nagano T (2011) Development of a highly sensitive fluorescence probe for hydrogen peroxide. J. Am. Chem. Soc., 133 (27) 10629-10637.

9. Jiao T., Leca-Bouvier BD., Boullanger P., Blum LJ., Girard-Egrot AP (2008) Electrochemiluminescent detection of hydrogen peroxide using amphiphilic luminol derivatives in solution. Colloids and Surfaces A: Physicochem. Eng. Aspects, 321 (1-3) 143-146.

10. Pappas AC., Stalikas CD., Fiamegos YC., Karayannis MI (2002) Determination of hydrogen peroxide by using a flow injection system with immobilized peroxidase and long pathlength capillary spectrophotometry. Analytica Chimica Acta, 455 (2) 305-313.

11. Yu A., Wang Q., Yong J., Mahon PJ., Malherbe F., Wang F., Zhang H., Wang J (2012) Silver nanoparticlecarbon nanotube hybrid films: preparation and electrochemical sensing. Electrochimica Acta, 74 111-116.

12. Yang Z., Qi C., Zheng X., Zheng J (2016) Sensing hydrogen peroxide with a glassy carbon electrode modified with silver nanoparticles, $\mathrm{AlOOH}$ and reduced graphene oxide. Microchim Acta, 183 (3) 11311136.

13. Feng L., Gao G., Huang P., Wang X., Zhang C., Zhang J., Guo S., Cui D (2011) Preparation of Pt-Ag alloy nanoisland/graphene hybrid composites and its high stability and catalytic activity in methanol electrooxidation. Nanoscale Res. Lett., 6 (1) 1-10.

14. Rajabzade H., Daneshgar P., Tazikeh E., Mehrabian RZ (2012) Functionalized carbonnanotubes with gold nanoparticles to fabricate a sensor for hydrogen peroxide determination. E-J. Chemistry, 9 (4) 2540-2549.

15. Liu X., Xu X., Zhu H., Yang X (2013) Synthesis of graphene nanosheets with incorpo-rated silver nanoparticles for enzymeless hydrogen peroxide detection. Anal. Methods, 5 (9) 2298-2304.

16. Wang Q, Yun Y (2013) Nonenzymatic sensor for hydrogen peroxide based on the elec-trodeposition of silver nanoparticles on poly (ionic liquid)-stabilized graphene sheets. Microchim Acta 180 (3-4) 261-268.

17. Yu B., Feng J., Liu S., Zhang T (2013) Preparation of reduced graphene oxide deco-rated with high density $\mathrm{Ag}$ nanorods for nonenzymatic hydrogen peroxide detection. RSC Adv., 3 (34) 14303-14307.

18. Tian L., Xia K., Hu W., Zhong X., Chen Y., Yang C., He G., Su Y., Li L (2017) A wide linear range and stable $\mathrm{H} 2 \mathrm{O} 2$ electrochemical sensor based on $\mathrm{Ag}$ decorated hierarchical $\mathrm{Sn}_{3} \mathrm{O}_{4}$. Electrochimica Acta, 231 190-199.

19. Nia PM., Meng WP., Alias Y (2015) Hydrogen peroxide sensor: Uniformly decorated silver nanoparticles on polypyrrole for wide detection range. Applied Surface Science, 357 (B) 1565-1572.

20. Lorestani F., Shahnavaz Z., Mn P., Alias Y., Manan NSA (2015) One-step hydrothermal green synthesis of silver nanoparticles carbonnanotube reduced-graphene oxide composite and its application as hydrogen peroxide sensor. Sensors and Actuators B, 208 389-398.

21. Golsheikh AM., Huang NM., Lim HN., Zakaria R., Yin CY (2013) One-step electrodeposition synthesis of silver-nanoparticle-decorated graphene on indium-tin-oxide for enzymeless hydrogen peroxide detection. Carbon, 62 405-412.

22. Abdolhosseinzadeh S., Asgharzadeh H., Kim HS (2015) Fast and fully-scalable synthesis of reduced graphene oxide. Sci. Rep., 5 1-7.

23. Zhang Y., Liu S., Wang L., Qin X., Tian J., Lu W., Chang G., Sun X (2012) One-pot green synthesis of Ag nanoparticles-graphene composites and their applications in SERS, $\mathrm{H}_{2} \mathrm{O}_{2}$, and glucose sensing. RSC Advances, 2 538-545. 
24. Liu S., Tian J., Wang L., Sun X (2011) A method for the production of reduced graphene oxide using benzylamine as a reducing and stabilizing agent and its subsequent decoration with Ag nanoparticles for enzymeless hydrogen peroxide detection. Carbon, 49 3158-3164.

25. Zhao B., Liu Z., Fu W., Yang H (2013) Construction of 3D electrochemically reduced graphene oxide silver nanocomposite film and application as nonenzymatic hydrogen peroxide sensor. Electrochemistry Communications, 27 1-4.

26. Welch CM., Banks CE., Simm AO., Compton RG (2005) Silver nanoparticle assemblies supported on glassy carbon electrodes for the electro-analytical detection of hydrogen peroxide. Anal Bioanal Chem, 382 (1) 1221.

27. Shendage SS., Patil UB., Nagarkar JM (2013) Electrochemical deposition of Highly Dispersed Palladium Nanoparticles on Nafion-Graphene Film in Presence of Ferrous ions for Ethanol Electrooxidation. Fuel Cells, 13 (3) 364-370.

28. Zhao L., Wang Y., Zhao X., Deng Y., Li Q., Xia Y (2018) Green Preparation of Ag-Au Bimetallic Nanoparticles Supported on Graphene with Alginate for Non-Enzymatic Hydrogen Peroxide Detection. Nanomaterials, 8 (7) 507.

29. Zhang K., Chen X., Li Z., Wang Y., Sun S., Wang L., Guo T., Zhang D., Xue Z., Zhou X., Lu X., Xue Z (2018) $\mathrm{Au}$-Pt bimetallic nanoparticles decorated on sulfonated nitrogen sulphur co-doped graphene for simultaneous determination of dopamine and uric acid. Talanta, 178 315-323.

30. Noor AM., Shahid MM., Rameshkumar P., Huang NM (2016) A glassy carbon electrode modified with graphene oxide and silver nanoparticles for amperometric determination of hydrogen peroxide. Microchim Acta, 183 (2) 911-916.

31. Feng W., Yang L., Cao N., Du C., Dai H., Luo W., Cheng G (2014) In situ facile synthesis of bimetallic CoNi catalyst supported on graphene for hydrolytic dehydrogenation of amine borane. Int. J. Hydrogen Energy, 39 (7) 3371-3380.

32. Zhang W., Qiao X., Chen J (2006) Synthesis and characterization of silver nanoparticles in AOT microemulsion system. Chemical Physics, 330 (3) 495-500.

33. Zhao F., Zhou M., Wang L., Huang Z., Chu Y (2019) One-step voltammetric deposition of 1-proline assisted silver nanoparticles modified glassy carbon electrode for electrochemical detection of hydrogen peroxide. $J$. Electroanalytical Chemistry, 833 205-212.

34. Zhou Y., Yin H., Meng X., Xu Z., Fu Y., Ai S (2012) Direct electrochemistry of sarcosine oxidase on graphene, chitosan and silver nanoparticles modified glassy carbon electrode and its biosensing for hydrogen peroxide. Electrochimica Acta, 71 294-301.

35. Anandalakshmi K., Venugobal J., Ramasamy V (2016) Characterization of silver nanoparticles by green synthesis method using Pedalium murex leaf extract and their antibacterial activity. Appl Nanosci, 6 (3) 399408.

36. Ganesan V., Deepa B., Nima P., Astalakshmi A (2014) Bio-inspired of silver nanoparticles using leaves of Millingtonia hortensis L.f. J. Adv. Biotechnol. And Res., 5 (2) 93-100.

37. Park HH., Zhang X., Choi YJ., Park HH., Hill RH (2011) Synthesis of Ag Nanostructures by Photochemical Reduction Using Citrate-Capped Pt Seeds. J. Nanomaterials, 2011 1-7.

38. C. Li., Y. Yao (2020) Synthesis of bimetallic core-shell silver-copper nanoparticles decorated on reduced graphene oxide with enhanced electrocatalytic performance. Chemical Physics Letters, 761137726.

39. D. Li., L. Meng., P. Xiao., D. Jiang., S. Dang., M. Chen (2017) Enhanced non-enzymatic electrochemical sensing of hydrogen peroxide based on $\mathrm{Cu} 2 \mathrm{O}$ nanocubes/Ag-Au alloy nanoparticles by incorporation of RGO nanosheets. J. Electroanalytical Chemistry, 791 23-28.

40. J. Li., J. Jiang., Z. Xu., M. Liu., S. Tang., C. Yang., D. Qian (2018) with enhanced electrocatalytic activity for ultrasensitive detection of H2O2. Sensors and Actuators B, 260 529-540.

41. X. Qina, Y. Luoa., W. Lua., G. Changa., AM. Asiri., AO. Al-Youbi., X. Sun (2012) One-step synthesis of Ag nanoparticles-decorated reduced graphene oxide and their application for $\mathrm{H}_{2} \mathrm{O}_{2}$ detection. Electrochimica Acta, 79 46-51.

42. H. Wadhwa., D. Kumara., S. Mahendia., S. Kumar (2017) Microwave assisted facile synthesis of Reduced Graphene Oxide-Silver (RGO-Ag) Nanocomposite and their application as active SERS substrate. Materials Chemistry and Physics, 194 274-282.

43. Liu GF., Huang LJ., Wang YX., Tang JG., Wang Y., Cheng MM., Zhang Y., Kipper MJ., Belfiore LA., Ranilc WS (2017) Preparation of a graphene/silver hybrid membrane as a new nanofiltration membrane. RSC Adv., 7 (77) 49159-49165. 
44. Sun XF., Qin J., Xia PF., Guo BB., Yang CM., Song C., Wang SG (2015) Graphene oxide-silver nanoparticle membrane for biofouling control and water purification. Chem. Eng. J., 281 53-59.

45. He D., Garg S., Waite TD (2012) $\mathrm{H}_{2} \mathrm{O}_{2}$-Mediated Oxidation of Zero-Valent Silver and Resultant Interactions among Silver Nanoparticles, Silver Ions, and Reactive Oxygen Species. Langmuir, 28 (27) 10266 - 10275.

46. Sang S., Li D., Zhang H., Sun Y., Jian A., Zhang Q., Zhang W (2017) Facile synthesis of AgNPs on reduced graphene oxide for highly sensitive simultaneous detection of heavy metal ions. RSC Adv., 7 (35) 2161821624.

47. Han L., Liu CM., Dong SL., Du CX., Zhang XY., Li LH., Wei Y (2017) Enhanced conductivity of rGO/Ag NPs composites for electrochemical immunoassay of prostate- specific antigen. Biosensors and Bioelectronics, 87 466-472.

48. Kurowska TE., Gawlak K., Hnida K., Jaskuła M., Sulka GD (2016) Synthesis of porous thin silver films and their application for hydrogen peroxide sensing. Electrochimica Acta, 213 811-821.

49. Bas SZ (2015) Gold nanoparticle functionalized graphene oxide modified platinum electrode for hydrogen peroxide and glucose sensing. Mater. Lett., 150 20-23.

50. Tian J., Liu S., Sun X (2010) Supramolecular Microfibrils of o-Phenylenediamine Dimers: OxidationInduced Morphology Change and the Spontaneous Formation of Ag Nanoparticle Decorated Nanofibers. Langmuir, 26 (19) 15112-15116.

51. Maduraiveeran G., Kundu M., Sasidharan M (2018) Electrochemical detection of hydrogen peroxide based on silver nanoparticles via amplified electron transfer process. J. Mater. Sci., 53 (11) 8328-8338.

52. Tran HV., Le TA., Giang BL., Piro B., Tran LD (2019) Silver nanoparticles on graphene quantum dots as nanozyme for efficient $\mathrm{H}_{2} \mathrm{O}_{2}$ reduction in a glucose biosensor. Mater. Res. Express, 6 (11) 1-8.

53. Tran HV., Huynh CD., Tran HV., Piro B (2018) Cyclic voltammetry, square wave voltammetry, electrochemical impedance spectroscopy and colorimetric method for hydrogen peroxide detection based on chitosan/silver nanocomposite. Arabian J. Chemistry, 11 (4) 453-459.

54. Nguyen ND., Nguyen TV., Chu AD., Tran HV., Tran LT., Huynh CD (2018) A label-free colorimetric sensor based on silver nanoparticles directed to hydrogen peroxide and glucose. Arabian J. Chemistry, 11 (7) 1134-1143.

55. Sankarasubramanian K., Justice Babu K., Soundarrajan P., Logu T., Gnanakumar G., Ramamurthi K., Sethuraman K., Senthil Kumar SM (2019) A new catalyst Ti doped CdO thin film for non-enzymatic hydrogen peroxide sensor application. Sensors \& Actuators: B. Chemical 285 164-172.

56. Gnana kumar G., Justice Babu K., Nahm KS., Hwang YJ (2014) A facile one-pot green synthesis of reduced graphene oxide and its composites for nonenzymatic hydrogen peroxide sensor applications. RSC Adv., 4 7944.

57. Ramachandran K., Zahoor A., Raj Kumar T., Nahm KS., Balasubramani A., Gnana Kumar G (2017) MnO2 nanorods grown NGNF nanocomposites for the application of highly sensitive and selective electrochemical detection of hydrogen peroxide. J. Industrial and Engineering Chem. 46, 19-27.

58. Vasuki K., Justice Babu K., Sheet S., Siva G., Kim AR., Yoo DJ., Kumar GG (2017) Amperometric hydrogen peroxide sensor based on the use of $\mathrm{CoFe}_{2} \mathrm{O}_{4}$ hollow nanostructures. Microchimica Acta 8, 25792586.

59. Karthikeyan C., Ramachandran K., Sheet S., Yoo DJ., Lee YS., Kumar YS., Kim AR., Kumar GG (2017) Pigeon-Excreta-Mediated Synthesis of Reduced Graphene Oxide (rGO)/CuFe $\mathrm{O}_{4}$ Nanocomposite and Its Catalytic Activity toward Sensitive and Selective Hydrogen Peroxide Detection. ACS Sustainable Chem. Eng. 5, 4897-4905.

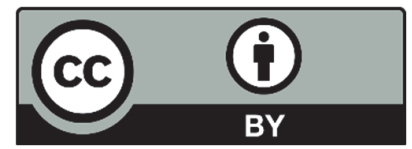

(C) 2021 by the authors; licensee Growing Science, Canada. This is an open access article distributed under the terms and conditions of the Creative Commons Attribution (CC-BY) license (http://creativecommons.org/licenses/by/4.0/). 